\title{
Leukemia Cutis in a 60 Year Male with Underlying Acute Myeloblastic Leukemia
}

\author{
ZULFIQAR HOSSAIN KHAN, ${ }^{1}$ MD. MAHABUBUR RAHAMAN, ${ }^{2}$ MD.ZAHED PARVEZ, ${ }^{3}$ TANVIR AHMED, ${ }^{4}$ \\ MD. SHAKHAWAT HOSSAIN, ${ }^{5}$ MAKHANLAL PAUL ${ }^{6}$
}

\begin{abstract}
Leukemia cutis is not a common manifestation of leukemia but when present it indicates poor prognosis. Here we report a case of an atypical presentation of acute myeloblastic leukaemia who presented with neurological features and skin eruption.
\end{abstract}

Keyword: AML, Leukaemia Cutis, Poor Prognosis

\section{Introduction:}

Cutaneous eruptions seen in patients with leukemia cutis may be divided into specific(leukemia cutis) and nonspecific lesions(reactive and infectious process).All forms of leukemia can be associated with cutaneous findingsbut it is more common in myeloid leukemia.Specific cuteneous eruptions are multiple papules or nodules $(60 \%)$ or infiltrated plaques $(26 \%)$. These lesions are erythematous,flash-coloured or violeceous. They are rubbery on palpation and ulceration is uncommon ${ }^{1}$. The diagnosis is made by clinical suspicion and varied by skin biopsy,immunophenotyping and $\mathrm{B}$ or $\mathrm{T}$ cell receptor rearrangement studies.Hematological studies with complete analysis of bone marrow aspirate and peripheral blood smear are then needed to make the diagnosis ${ }^{2}$.Blood examination usually shows anaemia with a normal or raised MCV.The leukocyte count may vary from as low as $1 \times 10^{9 /}$ Lto as high as $50010^{9} / \mathrm{L}$ or more. In the majority of patients the count is below100x109/L.Severe thrombocytopenia is usual but not invariable. The appearance of blast cells in the blood film is usually diagnostic. Sometime the blast count may be very low in peripheral blood and a bone marrow examinations necessary to confirm the diagnosis.Bone marrow is usually hyper cellularwith replacement of normal elements by leukemic blast cell in varying degrees (but more than $20 \%$ of the cells). The presence of Auer rods in the cytoplasm of blast cells indicate a myeloblastic type of leukemia ${ }^{4}$.Skin biopsy for histopathology in early acute

1. Assistant Professor, Dhaka Medical College, Dhaka.

2. Assistant Professor, Central Medical College, Comilla.

3. Assistant Professor, Dhaka Medical College, Dhaka.

4. Assistant Registrar, Dhaka Medical College, Dhaka.

5. Medical Officer, Dhaka Medical College, Dhaka.

6. Assistant Professor, Central Medical College, Comilla.

Correspondence : Dr. ZulfiqarHossain Khan, Assistant Professor, Dhaka Medical College, Dhaka. myelogenous leukemia cutis may produce an angiocentric infiltrate, although interstitial permeation among collagen bundles within the reticular dermis soon supervenes. Vague nodules may form as the dermis becomes progressively expanded by malignant cells, which express myeloperoxidase. Malignant myeloid cells forming the dominant cell type of acute myeloid leukemia cutis tend to appear monotonous and homogeneous cytologically. Nuclei are round to oval, chromatin may be evenly dispersed, and nucleoli are multiple but potentially inconspicuous. On rare occasion, immature eosinophils containing typical cytoplasmic granules in the absence of bilobed nuclear contours may be helpful in assigning a presumptive diagnosis ${ }^{3}$. The prognosis of leukemia cutis is directly related to the prognosis for systemic disease.Therapy is usually directed at the leukemia itself $^{2}$

\section{Case report:}

A 60 year old male was admitted in the department of medicine in DMCH with multiple skin coloured papules over scalp,face,trunk and proximal extremities for 03 months with generalized weakness and acute retention of urine. Initially the patient noticed sudden eruption of multiple papules on scalp and face. Rapidly lesions spread throughout the trunk and proximal upper extremities.Lesions are painless and nonpruritic.There is no history of fever,weight loss,gum bleeding or bony tenderness.

Physical examination revealed severe anemia.There is no lymphadenopathy.Examination of the integumentary system revealed multiple skin coloured papules on scalp, face, proximal upper extremities and throughout the trunk. Lesions are nontender and hard in consistency. Abdominal examination revealed moderate hepatomegaly but no splenomegaly or ascitis. Other systemic examination revealed no abnormalities. 


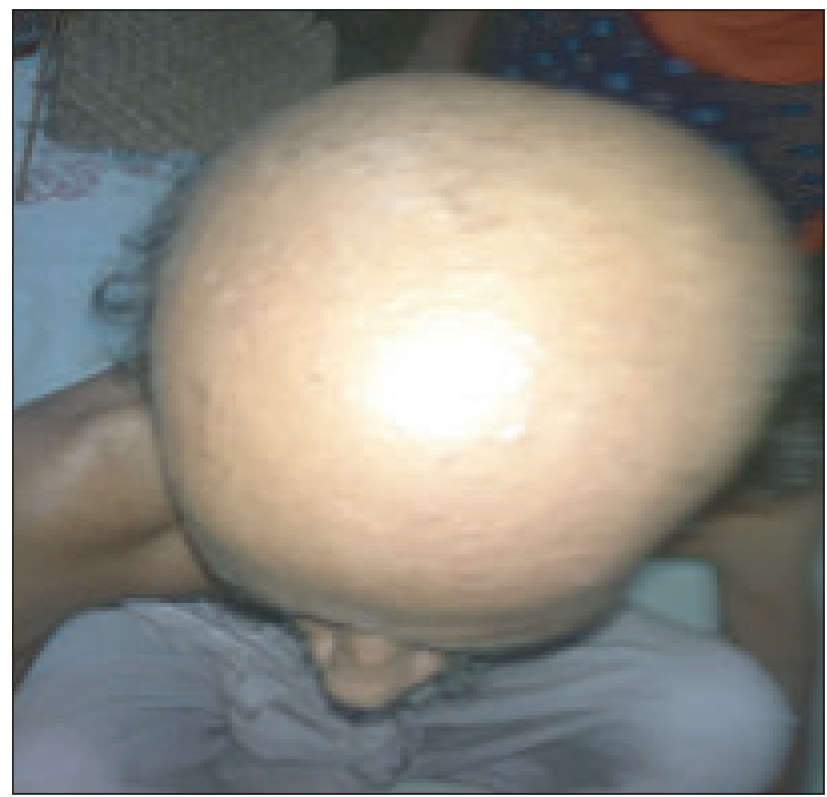

Fig.-1: Multiple skin coloured infiltrated papules throughout the scalp

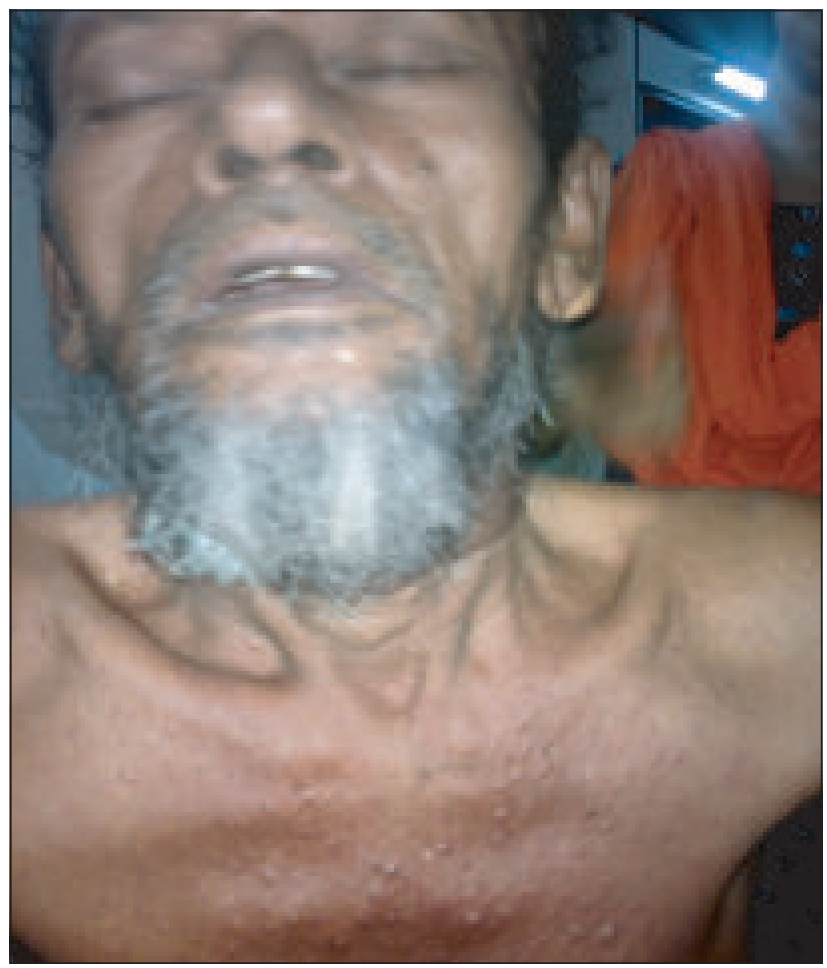

Fig.-2 : Multiple skin coloured papules throughout the upper trunk and neck.

Investigations revealed-Complete blood picture shows $\mathrm{Hb} \%$ $5.5 \mathrm{mg} / \mathrm{dl}$, ESR- $88 \mathrm{~mm}$ in $1^{\text {st }}$ hour, Total count of WBC- $4500 /$ cu mm differential count- $45 \%$ atypical cells.Platelet count$150000 / \mathrm{cu} \mathrm{mm}$.PBF shows shift to the left with predominance of atypical mononuclear cells features suggestive of acute myeloblastic leukemia.

Lesional skin biopsy revealed infiltration of blast cells in dermis.Epidermis appeared normal.Bone marrow study showed plenty number of medium to large sized blasts having high N/C ratio,abundant basophilic cytoplasm,loose

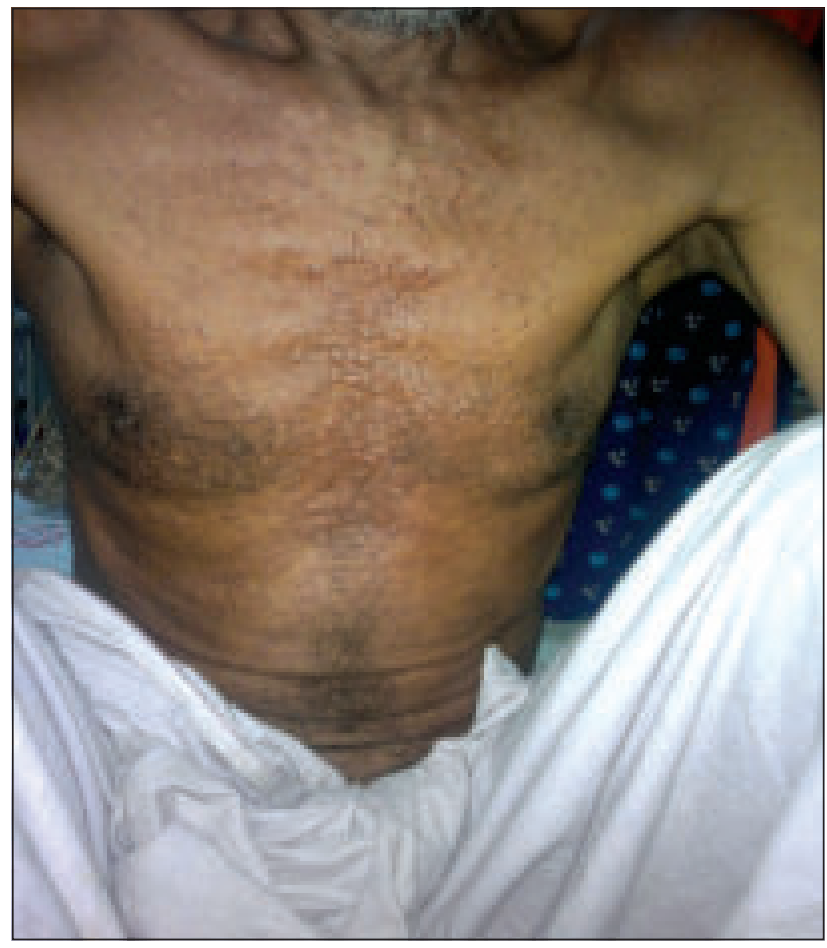

Fig.3: Multiple skin coloured papules throughout the anterior chest andabdumen.

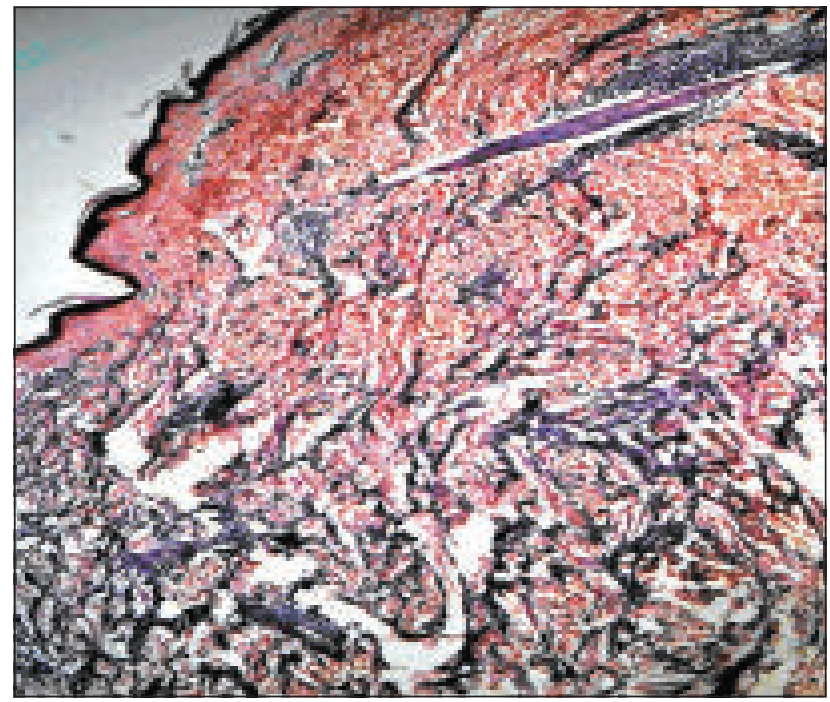

Fig.-4: Histopathology of leukemia cutis(Epidermis revealed normal,Dermis shows infiltrated blast cells) 


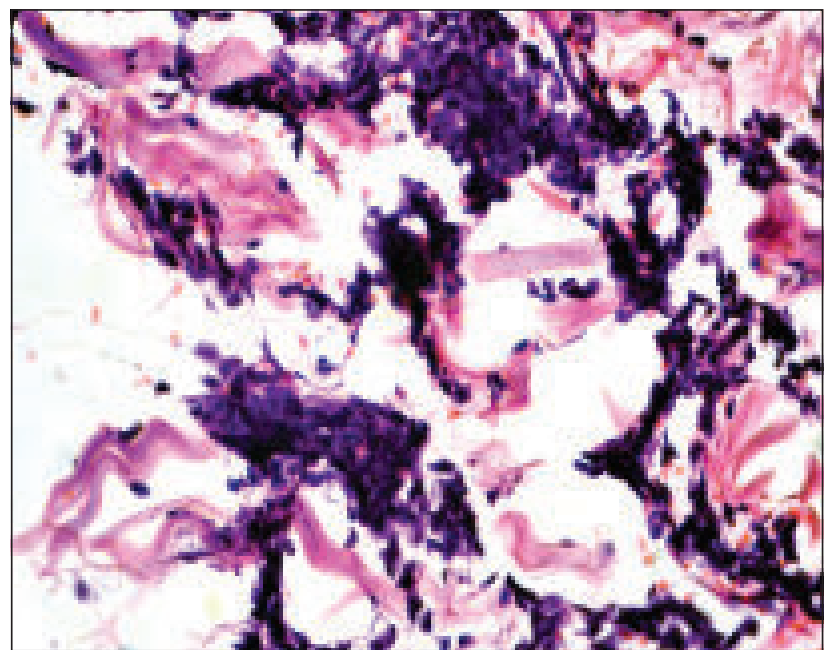

Fig.-5: Multiple infiltrated blast cells in dermis

chromatin,prominent nucleoli resembling myeloblasts.

The patient was given 2 units of blood transfusion for correction of severe anemia.Unfortunately he was discharged with risk bond and failed to treat and followed up properly.

\section{Discussion:}

A literature review showed that leukaemia cutis confined to the skin is extremely rare and commonly misdiagnosed. 8,9 Its a poor prognostic sign. Cutaneous involvement with acute leukaemia is fairly uncommon and usually a relatively late event. Skin lesions in acute leukaemia may be specific, called leukaemia cutis, or non-specific, called leukaemids that include leukocytoclastic vasculitis, Sweet's syndrome, urticaria, Erythroderma and erythema nodosum. In a study of 42 patients with specific leukaemic infiltrates, Su et $\mathrm{al}^{5}$ found that the most common lesions to be multiple papules and nodules (60\%) andinfiltrated plaques (26\%), with less frequent occurrence of macules, ulcers, ecchymoses, and palpable purpura. Leukaemia cutis occurs in about $20 \%$ of patientswith acute monocyticleukaemia(FAB-M5), ${ }^{6}$ and is uncommonly seen in other forms of AML.

Ittypically manifests as red or violaceous papules or nodules, mainly on the face, and can become purpuric with coexisting thrombocytopenia, and is generallyasymptomatic. Skin infiltration favours the lower dermis and subcutaneous fat with prominent involvement of adnexal structures, nerves, vessels of the superficial and deep plexus as noted in the present case. Skin involvement is not related tothe circulating white-cell count but the skin can act as a sanctuary for leukaemic cells. Leukaemia cutis generally carries a poor prognosis, with a high incidence of extramedullary disease at other sites including the meninges, and with imminentbone marrow relapses and serial skin relapses. As observed in a previous report, standard induction chemotherapy for AML is less effective in patients who have cutaneous involvement. Nevertheless, with curative therapy directed at skin, bone marrow, and other sites of extramedullary involvement,longterm disease-free survival is possible. ${ }^{7}$

We herein described a patient with AML who presented with asymptomatic extensive skincoloured papules on scalp,face,trunk and proximal upper extremities as the initial clinical manifestation of the disease. This report represents one of the few cases of AML presenting with leukemia cutis.

\section{Conflict of Interest : None}

\section{References}

1. JamesWD,BergerTG,ElstonDM.Andrews' Diseases of the skin. $11^{\text {th }}$ Ed. Philadelphia. WB Saunder's Company; 2011:736-37

2. Fredberg IM, Eisen AZ, Wolf K, Austen KF, Goldsmith LA, Katz SI. eds. Fitzpatricks Dermatology in General Medicine. $7^{\text {the }}$. Mcgraw-hill Comp, New York; 2008: 1385

3. Elder, David E.; Elenitsas, Rosalie; Johnson, Bernett L.; Murphy, George F.Lever's Histopathology of the Skin, 9th Edition,Lippincott Williams \& Wilkins;2005:970

4. NickiR.Colledge,Brian R Walker,StuartH.Ralston.Devidson's principles and practice of Medicine. $21^{\text {st }}$ Edition. Elsevier Limited; 2010:1032

5. Su WP, Buechner SA, Li Cy' Clinicopathologic correlations in leukemia cutis. JAmAcadDermatol 1984; 11: 121-8.

6. Baden TJ, Gammon WR. Leukemia cutis in acute myelomonocytic leukemia.Arch Dermatol 1987; 123:88-90.

7. Baer MR, Barcos M, Farrell H, Raza A, Preisler HD. Acute myelogenous leukemia with leukemia cutis: eighteen cases between 1969 and 1986. Cancer1989; 63:2192-200.

8. Wilkins R, Janes S. Aleukaemicleukaemia cutis: case report and review of the literature. Clin Lab Haematol 2004; 26(1): 73- 75 .

9. Byrd JC, EdenfieldWJ, Shields DJ, et al. Extramedullary myeloid cell tumors in acute nonlymphocytic leukemia: a clinical review. J ClinOncol 1995; 13: 1800- 1816. 